\title{
Catalytic Ozonation of Melanoidin in Aqueous Solution over $\mathrm{CoFe}_{2} \mathrm{O}_{4}$ Catalyst
}

\author{
Jivago Schumacher de Oliveira ${ }^{a}$,Julia da Silveira Salla ${ }^{a}$, Raquel Cristine Kuhn ${ }^{a}$, Sérgio Luiz Jahn ${ }^{a}$ \\ Edson Luiz Foletto ${ }^{a}$ (i) \\ aPrograma de Pós-Graduação em Engenharia Química, Universidade Federal de Santa Maria, 97.105- \\ 900, Santa Maria, RS, Brasil
}

Received: July 09, 2018; Revised: September 20, 2018; Accepted: October 08, 2018

In this work, cobalt ferrite $\left(\mathrm{CoFe}_{2} \mathrm{O}_{4}\right)$ was synthesized by solvothermal route for application as a catalyst in the ozonation reaction for the decolorization and mineralization of melanoidin from aqueous solution. The structural properties of $\mathrm{CoFe}_{2} \mathrm{O}_{4}$ sample were investigated by X-ray diffraction (XRD), nitrogen adsorption-desorption isotherms, Fourier-transform infrared spectroscopy (FTIR), particlesize distribution, scanning electron microscopy (SEM) and X-ray dispersive energy spectroscopy (EDS). Single-phase $\mathrm{CoFe}_{2} \mathrm{O}_{4}$ particles with a predominantly mesoporous structure containing a high specific surface area were obtained. Results showed that the $\mathrm{CoFe}_{2} \mathrm{O}_{4}$-catalyzed ozonation reaction has higher activity for the decolorization and mineralization of melanoidin when compared with the ozonation reaction without the presence of catalyst. Therefore, this material can be very promising for the application in catalytic ozonation systems for the melanoidin removal from liquid effluents.

Keywords: $\mathrm{CoFe}_{2} \mathrm{O}_{4}$, solvothermal, catalytic ozonation, melanoidin, decolorization, mineralization.

\section{Introduction}

The industrial distillation and fermentation processes for the production of ethanol, aminoacids and yeasts produce high volumes of wastewater containing high load of organic molecules, being characterized by high concentrations of biochemical oxygen demand (BOD5) and chemical oxygen demand (COD), and a dark brown color due to the presence of melanoidin molecule ${ }^{1-3}$. The biological treatment is generally used with a combination of anaerobic-aerobic processes in order to reduce $\mathrm{BOD}_{5}$ and $\mathrm{COD}$ of these wastewaters to acceptable levels. However, the dark brown color persists because only $6-7 \%$ of melanoidin is biodegraded by these conventional processes ${ }^{4}$. Melanoidin molecules are aminocarbonyl complex polymers containing a dark brown color, and formed from the non-enzymatic amino-carbonyl reactions taking place between the amino acid and sugars 5 . Therefore, colored compounds such as melanoidins when disposed in water bodies without an effective pre-treatment can reduce the penetration of light, preventing the photosynthesis of aquatic vegetation ${ }^{6}$. In addition, their mineralization towards $\mathrm{CO}_{2}$ and water is necessary in order to reduce the organic load, avoiding a damage to aquatic life ${ }^{4,5}$. Thus, recent efforts by researchers have been sought towards to more efficient treatment methods.

Advanced oxidative processes (AOPs) are currently known to be efficiently used for the degradation of organic pollutant molecules ${ }^{7-9}$. These processes are based on the generation of hydroxyl radicals $(\bullet \mathrm{OH})$, which are highly

*e-mail: efoletto@gmail.com reactive and can degrade many organic compounds ${ }^{10}$. Among the several existing AOPs methodologies ${ }^{11,12}$, ozonation process has been shown to be highly efficient in the degradation of several recalcitrant organic contaminants ${ }^{13-15}$. The chemical oxidation with ozone presents a high oxidative character, which is a fundamental property for the effluents treatment containing recalcitrant compounds, reaching satisfactory efficiency in the decomposition of organic pollutants, as in the case of melanoidin ${ }^{16}$.

The use of solid catalysts in the ozonation process (known as heterogeneous catalytic ozonation) promotes significant improvements in the organic matter degradation ${ }^{17}$. Furthermore, a solid catalyst can produce more powerful and unselective oxidant radicals, allowing that a high degradation rate to be achieved through the catalytic ozonation ${ }^{18}$. In the catalytic ozonation of organic compounds, ozone is firstly adsorbed onto the catalyst surface, and then decomposed to produce hydroxyl radicals $(\bullet \mathrm{OH})$ on the solid surface, where the organic pollutants may (or not) be adsorbed ${ }^{19,20}$. The adsorption of $\mathrm{O}_{3}$ and/or the organic molecule on the catalyst surface is a fundamental step in the catalytic ozonation ${ }^{21-23}$. Although there is experimental evidence to assume that heterogeneous catalytic ozonation involves the generation of hydroxyl radicals $(\bullet \mathrm{OH})$, some researchers reported the occurrence of direct reactions between molecular ozone and organic compounds adsorbed on the solid surface of the catalyst ${ }^{24}$.

Several materials have been reported as alternative catalysts for the ozonation process aiming the degradation of organic pollutants, such as $\mathrm{Al}_{2} \mathrm{O}_{3}{ }^{25}, \mathrm{MnO}_{2}{ }^{26}, \mathrm{MgO}^{27}$, ZSM-5 ${ }^{28}, \mathrm{SnO}_{2}{ }^{29}$ as well as catalysts supported on matrices in order to improve their catalytic properties ${ }^{30-32}$. However, 
a very few studies using $\mathrm{CoFe}_{2} \mathrm{O}_{4}$ as a catalyst in ozonation reaction have been reported in literature. $\mathrm{CoFe}_{2} \mathrm{O}_{4}$ particles were employed in Fenton/ozone oxidation process for the treatment of wastewater containing cytotoxic drugs ${ }^{33}$ and on the oxalic acid ozonation ${ }^{34}$. Moreover, so far, there is no report on the degradation of melanoidin using $\mathrm{CoFe}_{2} \mathrm{O}_{4}$ as catalyst in ozonation process.

In this context, this work aims to produce the cobalt ferrite and to evaluate its activity in heterogeneous catalytic ozonation for the degradation of melanoidin from aqueous solution.

\section{Materials and Methods}

\subsection{Preparation of synthetic melanoidin}

Synthetic melanoidin was prepared based on the methodology described by Dahiya et al. ${ }^{35}$. Firstly, $1 \mathrm{M}$ glucose, $1 \mathrm{M}$ amino acid and $0.5 \mathrm{M}$ sodium bicarbonate were dissolved in distilled water under magnetic stirring. After, the solution was placed into a Teflon-lined stainless steel autoclave and treatedat $120^{\circ} \mathrm{C}$ for $3 \mathrm{~h}$. Posteriorly, the obtained solution containing a dark brown color was filtered using a hollow fiber membrane (SLP-1053-10 kDa) (Pall Corporation, USA) coupled to the micro/ultrafiltration module (TE-0198, Tecnal, Brazil) to obtain melanoidin molecules with a molecular weight in the range of 1,000-10,000 Daltons. Then, the resultant filtrate of synthetic melanoidin was lyophilized (Liofilizator L101, Liobras, Brazil) in order to obtain the powdered melanoidin.

\subsection{Preparation of $\mathrm{CoFe}_{2} \mathrm{O}_{4}$}

Cobalt ferrite $\left(\mathrm{CoFe}_{2} \mathrm{O}_{4}\right)$ was synthesized by the solvothermal method using ethylene glycol as a solvent. Cobalt chloride ( $4 \mathrm{mmol}$; $\mathrm{CoCl}_{2} \cdot 6 \mathrm{H}_{2} \mathrm{O}$, Sigma-Aldrich) and ferric chloride ( $8 \mathrm{mmol} ; \mathrm{FeCl}_{3} .6 \mathrm{H}_{2} \mathrm{O}$, Sigma-Aldrich) were used in molar ratio of $1: 2=\mathrm{Co}: F e$. The cobalt and ferric chlorides salts were dissolved in $120 \mathrm{~mL}$ of ethylene glycol $\left(\mathrm{C}_{2} \mathrm{H}_{4} \mathrm{O}_{2}\right.$, Vetec $)$ under magnetic stirring, followed by the addition of $60 \mathrm{mmol}$ of sodium acetate $\left(\mathrm{NaC}_{2} \mathrm{H}_{3} \mathrm{O}_{2} \cdot 3 \mathrm{H}_{2} \mathrm{O}\right.$, Sigma-Aldrich). After, the resulting solution was transferred into the Teflon-lined stainless steel autoclave and subjected to a temperature of $200^{\circ} \mathrm{C}$ for $10 \mathrm{~h}$, and then cooled to room temperature. The solid particles were washed with distilled water and dried at $110^{\circ} \mathrm{C}$.

\subsection{Characterization of $\mathrm{CoFe}_{2} \mathrm{O}_{4}$}

The $\mathrm{CoFe}_{2} \mathrm{O}_{4}$ particles were characterized by X-ray diffraction (XRD), using a Rigaku Miniflex model 300 diffractometer, being operated with $\mathrm{Cu}-\mathrm{K} \alpha$ radiation $(\lambda=$ $1.5418 \AA$ ), $30 \mathrm{kV}, 10 \mathrm{~mA}$, step size of $0.03^{\circ}$ and a count time of $0.5 \mathrm{~s}$ per step. The pore properties were determined using a Micromeritics ASAP 2020 apparatus. The particle-size distribution was measured using a laser particle size analyzer
(Malvern Mastersizer 2000). The morphology and chemical analysis of the sample were obtained by scanning electron microscopy (SEM), using a FEI Inspect S50 apparatus coupled to an auxiliary Energy-Dispersive X-ray spectrometer (EDS) with secondary electron detector. FTIR spectrum of sample pressed into $\mathrm{KBr}$ pellet (10 mg $\mathrm{CoFe}_{2} \mathrm{O}_{4} / 300 \mathrm{mg} \mathrm{KBr}$ ) was recorded by a Shimadzu IR-Prestige- 21 spectrometer.

\subsection{Melanoidin degradation essays}

Melanoidin degradation essays were performed in a 300 $\mathrm{mL}$ glass reactor at $25^{\circ} \mathrm{C}$. Ozone gas was generated from the atmospheric air by an ozone generator apparatus (Ozone Generator, China). The ozone was fed into the reactor through a porous silica diffuser at the flow rate of $10 \mathrm{~mL} \mathrm{~min}^{-1}$. The residual ozone in the off-gas from the reactor was absorbed by a $10 \% \mathrm{Na}_{2} \mathrm{~S}_{2} \mathrm{O}_{3}$ aqueous solution. The schematic diagram of reaction system is shown in Figure 1. The reactor was filled with $200 \mathrm{~mL}$ of melanoidin aqueous solution (initial melanoidin concentration of $300 \mathrm{mg} \mathrm{L}^{-1}$; natural $\mathrm{pH}$ of solution $=6.85$ ) and $0.1 \mathrm{~g}$ of catalyst, and posteriorly submitted at magnetic stirring until the equilibrium adsorption was reached. Subsequently, ozone gas was fed into the reactor, and aliquots of the aqueous solution were collected at various time intervals and centrifuged for the separation of catalyst. For comparison purposes, the ozonation reaction without the presence of catalyst (non-catalytic ozonation) was also performed.

The decolorization efficiency of melanoidin was determined using a UV-Vis spectrophotometer (Bel Photonics, SP1105), with a maximum wavelength of $475 \mathrm{~nm}^{35}$. The decolorization efficiency was expressed by the ratio $C / C_{0}=\left(A / A_{0}\right)$ as a function of reaction time $t$, where: $C$ is the absorbance after a reaction time $t$, and $C_{0}$ is the initial absorbance before the reaction.

Total Organic Carbon (TOC) was measurement on a Shimadzu TOC-L CPH/CPN analyzer to determine the mineralization efficiency of melanoidin. The mineralization efficiency was expressed in terms of $T O C / T O C_{0}$ as a function of reaction time $t$, where: TOC is the carbon concentration after a reaction time $t$, and $T O C_{0}$ is the initial concentration before the reaction.

All the experimental essays were carried out in triplicate.

\section{Results and Discussion}

\subsection{Characterization of material}

Figure 2 shows the X-ray diffractogram of $\mathrm{CoFe}_{2} \mathrm{O}_{4}$ sample. From Figure 2, it is possible to observe that the peaks position $(2 \theta)$ and their intensities are similar to JCPDS card no. 22-1086, confirming the formation of single-phase $\mathrm{CoFe}_{2} \mathrm{O}_{4}$ particles. The diffraction peaks at $2 \theta$ of $18.1^{\circ}, 30.0^{\circ}$, $35.5^{\circ}, 37.0^{\circ}, 43.0^{\circ}, 53.0^{\circ}, 57,0^{\circ}$ and $62.6^{\circ}$ can be attributed to the diffraction planes (111), (220), (311), (222), (400), (422), (511) and (440), respectively. In addition, no impurities 


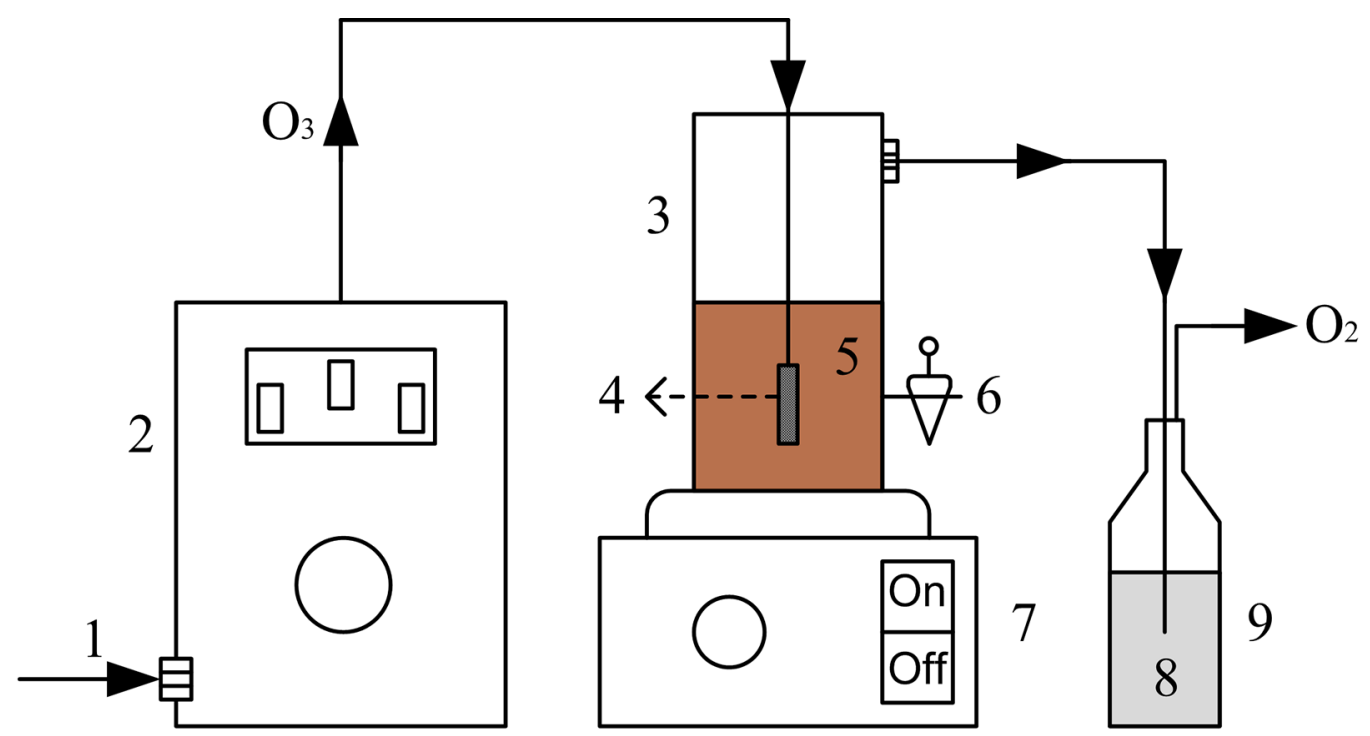

\title{
1 - Air inlet \\ 4 - Porous diffusior \\ 2 - Ozone generator \\ 5 - Melanoidin solution \\ 6 - Sample collector \\ 3 - Reactor
}

\author{
7 - Magnetic stirrer \\ $8-\mathrm{Na}_{2} \mathrm{~S}_{2} \mathrm{O}_{3}$ solution \\ 9 - Ozone destruction unit
}

Figure 1. Schematic diagram of reaction system.

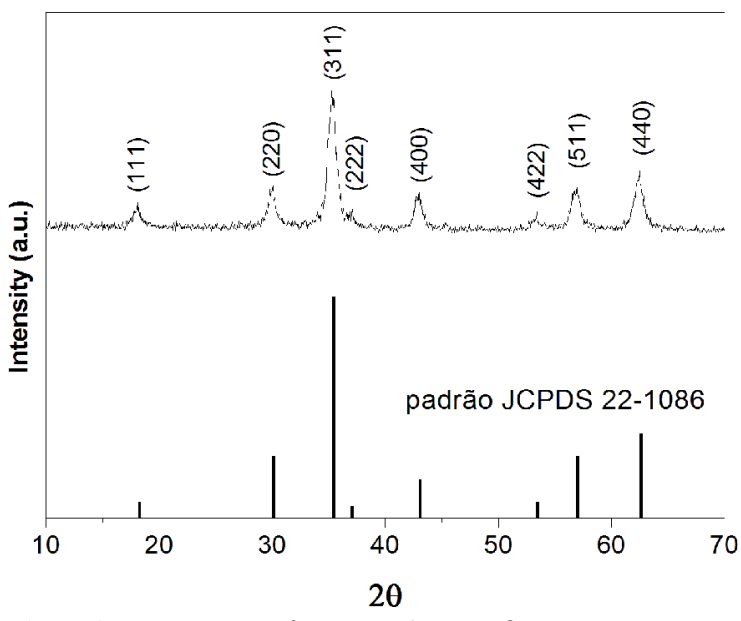

Figure 2. XRD pattern of $\mathrm{CoFe}_{2} \mathrm{O}_{4}$ (Inset at figure: $\mathrm{B}$ arsrepresent the $\mathrm{CoFe}_{2} \mathrm{O}_{4}$ reference according to JCPDS card no. 22-1086).

peaks are observed in diffractogram, evidencing thus the formation of a single-phase $\mathrm{CoFe}_{2} \mathrm{O}_{4}$ sample.

Figure 3 shows the nitrogen adsorption-desorption isotherms (Figure 3a) and pore-size distribution curve (Figure 3b) of $\mathrm{CoFe}_{2} \mathrm{O}_{4}$ sample. The nitrogen adsorption-desorption isotherms (Figure $3 \mathrm{a}$ ) of $\mathrm{CoFe}_{2} \mathrm{O}_{4}$ sample can be categorized as type IV with an $\mathrm{H} 1$ hysteresis loop (according to the IUPAC classification), which indicates the predominance of mesoporous particles. The behavior of size-pore distribution curve (Figure $3 \mathrm{~b}$ ) confirms the presence of mesoporous structure, since the distribution is predominantly located on the mesoporous region $(2 \mathrm{~nm}<$ pore size $<50 \mathrm{~nm})$. The found values for the specific surface area, total pore volume and average pore size were $116 \mathrm{~m}^{2} \mathrm{~g}^{-1}, 0.282 \mathrm{~cm}^{3} \mathrm{~g}^{-1}$ and 8.90 $\mathrm{nm}$, respectively. Kalam et al. ${ }^{36}$ found a surface area value of $76 \mathrm{~m}^{2} \mathrm{~g}^{-1}$ for the $\mathrm{CoFe}_{2} \mathrm{O}_{4}$ particles prepared by modified solvothermal process with polysaccharide, whereas Srivastava et al. ${ }^{37}$ found a value of $41.3 \mathrm{~m}^{2} \mathrm{~g}^{-1}$ through the modified co-precipitation method. $\mathrm{CoFe}_{2} \mathrm{O}_{4}$ particles prepared by sol-gel ${ }^{38}$ and hydrothermal ${ }^{39}$ methods presented surface area values of $10 \mathrm{~m}^{2} \mathrm{~g}^{-1}$ and $85 \mathrm{~m}^{2} \mathrm{~g}^{-1}$, respectively. Some works in literature demonstrate that the synthesis of materials through the solvothermal route using diols as solvents promotes very interesting physical properties to the material ${ }^{40,41}$. Therefore, the synthesis method employed herein promoted $\mathrm{CoFe}_{2} \mathrm{O}_{4}$ particles with a highlighted value of surface area, which is primordial for catalytic purposes.

Figure 4 shows the particle-size distribution curve of $\mathrm{CoFe}_{2} \mathrm{O}_{4}$ sample. A wide range of particle-size was observed for the sample, being between 0.55 and $125 \mu \mathrm{m}$, resulting in a Sauter mean diameter of $27 \mu \mathrm{m}$.

FTIR spectrum of $\mathrm{CoFe}_{2} \mathrm{O}_{4}$ is shown in Figure 5. The broad band at about $3423 \mathrm{~cm}^{-1}$ is ascribed to stretching mode of $\mathrm{O}-\mathrm{H}$ group of the free and absorbed water. Bands at $1080 \mathrm{~cm}^{-1}$ and $1600 \mathrm{~cm}^{-1}$ are associated with the presence of humidity absorbed on the $\mathrm{CoFe}_{2} \mathrm{O}_{4}$ sample. The band at $2340 \mathrm{~cm}^{-1}$ corresponds to adsorbed $\mathrm{CO}_{2}$ from the air. A strong absorption near $575 \mathrm{~cm}^{-1}$ is attributed to the octahedral cation group complex $\left(\mathrm{Co}^{2+}-\mathrm{O}^{2-}\right)$ vibration mode of cobalt ferrite nanoparticles ${ }^{42,43}$. 

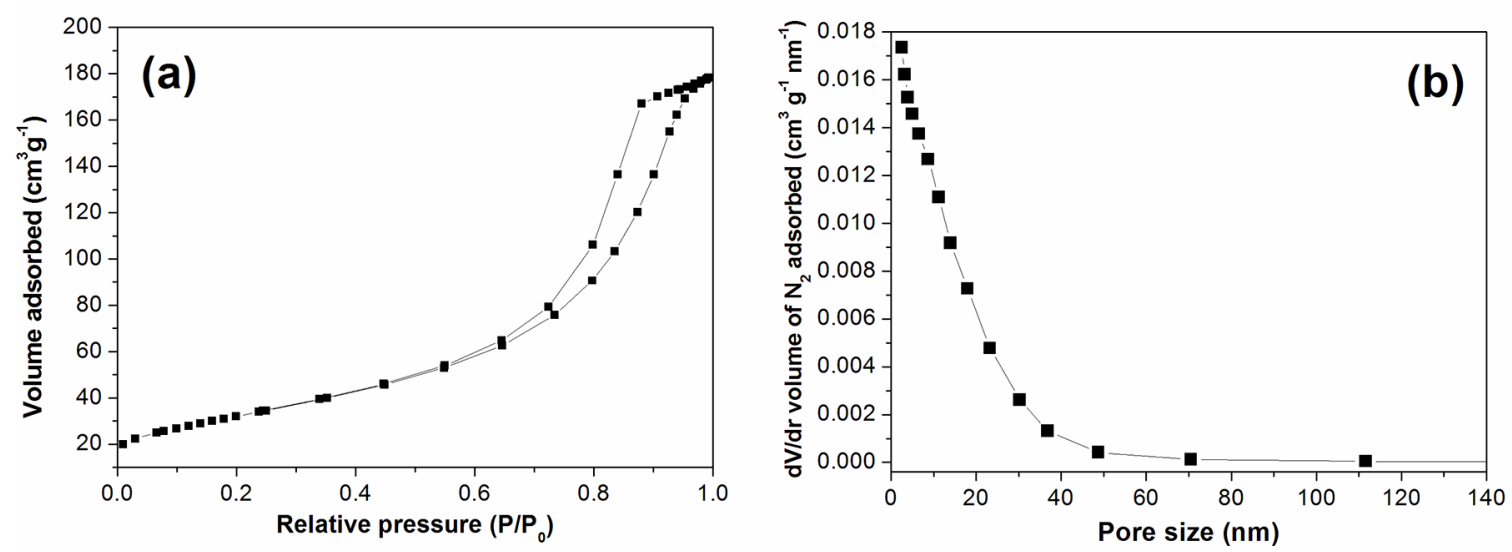

Figure 3. $\mathrm{N}_{2}$ adsorption/desorption isotherms (a), and pore-size distribution curve (b) of $\mathrm{CoFe}_{2} \mathrm{O}_{4}$ sample.

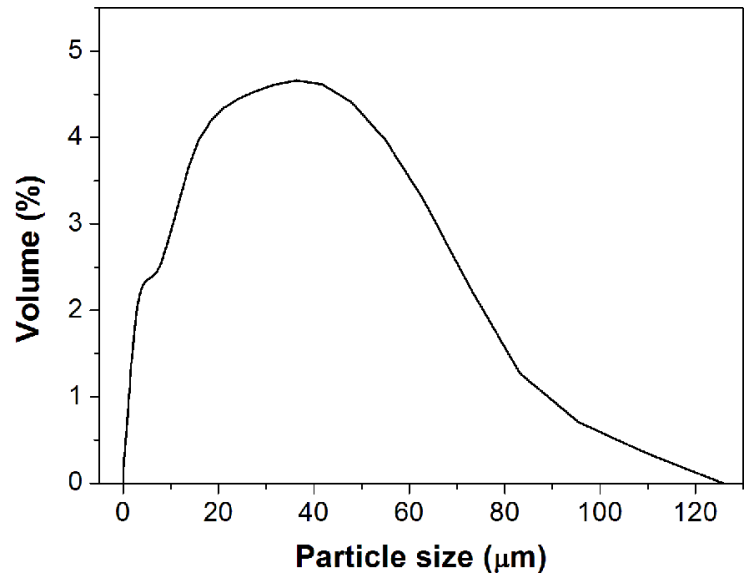

Figure 4. Particle-size distribution curve of $\mathrm{CoFe}_{2} \mathrm{O}_{4}$.

Figure 6 shows SEM image (Figure 6a) and EDS analysis (Figure 6b) of $\mathrm{CoFe}_{2} \mathrm{O}_{4}$ sample. From Figure 6a, it is possible to observe that the particles have irregular shapes and are partially agglomerated. In addition, different particle sizes can be observed, corroborating the result from the particle-size distribution analysis (Figure 4). Elemental analysis (Figure 6b) of $\mathrm{CoFe}_{2} \mathrm{O}_{4}$ was obtained from the point marked on the SEM image (Figure 6a), where an approximate atomic ratio $\mathrm{Co}: \mathrm{Fe}$ $=1: 2$ was found, which is according to the stoichiometric composition in the formula $\mathrm{CoFe}_{2} \mathrm{O}_{4}$. Therefore, this result evidences the formation of $\mathrm{CoFe}_{2} \mathrm{O}_{4}$ phase, corroborating the results from the XRD analysis (Figure 2).

Figure 7 shows the image of $\mathrm{CoFe}_{2} \mathrm{O}_{4}$ particles attracted by a magnet. Due to their magnetic properties ${ }^{42,44}, \mathrm{CoFe}_{2} \mathrm{O}_{4}$ particles can be easily separated and recovered from the aqueous solution by a magnetic field for further reutilization.

\subsection{Catalytic and non-catalytic essays}

Figure 8 shows the melanoidin decolorization results using non-catalytic $\left(\mathrm{O}_{3}\right.$ alone $)$ and catalytic $\left(\mathrm{O}_{3} / \mathrm{CoFe}_{2} \mathrm{O}_{4}\right)$ ozonation processes. In addition, no melanoidin adsorption on the catalyst surface was observed, as shown in Figure 8. The data obtained in this study clearly indicate that the catalytic ozonation of melanoidin in the presence of $\mathrm{CoFe}_{2} \mathrm{O}_{4}$ shows remarkable decolorization efficiency (98\%) when compared with the non-catalytic ozonation (75\%).

The apparent rate constants for the melanoidin decolorization by catalytic $\left(\mathrm{O}_{3} / \mathrm{CoFe}_{2} \mathrm{O}_{4}\right)$ and non-catalytic $\left(\mathrm{O}_{3}\right)$ ozonation processes were estimated by linear regression, as shown in Figure 9. Both the processes followed the pseudo-first-order kinetics, according to Equation (1). ${ }^{45,46}$

$$
\ln \left(\frac{C}{C_{0}}\right)=k_{d} t
$$

where, $k_{d}$ the apparent rate constant for the melanoidin decolorization, which is obtained from the slope of the respective linear plots.

From Figure 9, the apparent rate constants for the melanoidin decolorization from the $\ln \left(\mathrm{C} / \mathrm{C}_{0}\right)$ versus time for the non-catalytic $\left(\mathrm{O}_{3}\right)$ and catalytic $\left(\mathrm{O}_{3} / \mathrm{CoFe}_{2} \mathrm{O}_{4}\right)$ ozonation processes were obtained. The reaction constants values were $51 \times 10^{-3} \mathrm{~min}^{-1}\left(R^{2}=0.97\right)$ and $101 \times 10^{-3} \mathrm{~min}^{-1}\left(R^{2}=0.99\right)$ for the non-catalytic $\left(\mathrm{O}_{3}\right)$ and catalytic $\left(\mathrm{O}_{3} / \mathrm{CoFe}_{2} \mathrm{O}_{4}\right)$ ozonation reactions, respectively. Therefore, the presence of $\mathrm{CoFe}_{2} \mathrm{O}_{4}$ on the reaction medium promoted a highest catalytic activity, exhibited a reaction rate about two times faster than that of the non-catalytic ozonation reaction.

Figure 10 shows the color of melanoidin solutions during the catalytic ozonation reaction $\left(\mathrm{O}_{3} / \mathrm{CoFe}_{2} \mathrm{O}_{4}\right)$. The respective figure was obtained by the digital camera. The first sample (indicated as " 0 ") corresponds to melanoidin solution before the reaction. The respective solution presents a dark brown color, which is characteristic of melanoidin molecule. The melanoidin decolorization progressively increased as function of reaction time, being that at the end of $30 \mathrm{~min}$, a practically transparent solution is observed. Therefore, the color removal can be attributed to the fact that the $\mathrm{O}_{3}$ / $\mathrm{CoFe}_{2} \mathrm{O}_{4}$ system is able to cleavage the conjugated carboncarbon double bonds presents in the melanoidin structure, which are responsible for the brown color ${ }^{47}$. 
In order to verify the species responsible for the melanoidin decolonization, isopropanol, p-benzoquinone and triethanolamine were employed as scavengers for hydroxyl radicals $(\cdot \mathrm{OH})$, superoxide anion radicals $\left(\mathrm{O}_{2}^{-}\right)$and photogenerated holes $\left(\mathrm{h}^{+}\right)$, respectively $\mathrm{y}^{48,49,50}$. The experiments were carried out under similar conditions those for the nonscavenging experiments. Through the preliminary essays using p-benzoquinone and triethanolamine in the reaction, no change in melanoidin color was observed when compared to the non-scavenging experiment. On the other hand, a significant change in melanoidin color occurred under the presence of isopropanol. Therefore, these results indicate that the hydroxyl radicals $(\bullet \mathrm{OH})$ are the oxidative species involved in the melanoidin degradation by catalytic ozonation.

Figure 11 shows the effect of scavenger (isopropanol) on the melanoidin decolorization at $30 \mathrm{~min}$ of reaction time. The results show that the presence of isopropanol leads to a decrease in the melanoidin decolorization around 26\% for the catalytic ozonation process, indicating that $\bullet \mathrm{OH}$ is an important active radical involved in this process. On the order hand, the addition of isopropanol did not impact the melanoidin decolorization for the $\mathrm{O}_{3}$ alone. Therefore, these results indicate that in the absence of catalyst, the direct mechanism by molecular $\mathrm{O}_{3}$ (direct reaction) occurred,

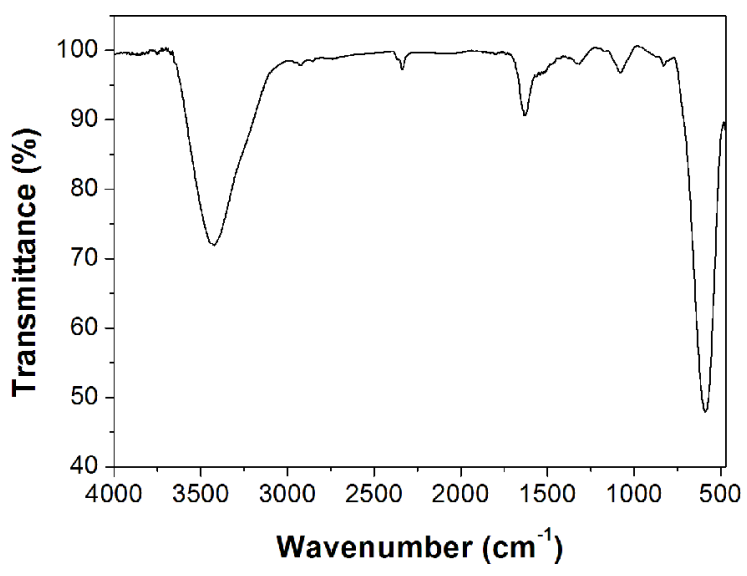

Figure 5. FTIR spectrum of $\mathrm{CoFe}_{2} \mathrm{O}_{4}$. whereas in the presence catalyst, there was a major contribution of oxidant specie $(\cdot \mathrm{OH})$. In addition, the results showed that the catalytic ozonation reaction with the scavenger (isopropanol) was not be completely quenched, indicating that the $\cdot \mathrm{OH}$ is not the only species involved in melanoidin decolorization. In this case, direct ozonation reaction also occurred. Therefore, the presence of $\mathrm{CoFe}_{2} \mathrm{O}_{4}$ catalyst on the ozonation reaction promoted the formation of $\bullet \mathrm{OH}$ radicals in the reaction medium, resulting in greater efficiency of melanoidin decolorization. Recently, it has been reported that the presence of solid catalyst in the ozonation process could increase the generation of radicals and the oxidation of organic compounds due to the formation of hydroxyl radicals $(\cdot \mathrm{OH})$ in the reaction medium, which has a higher

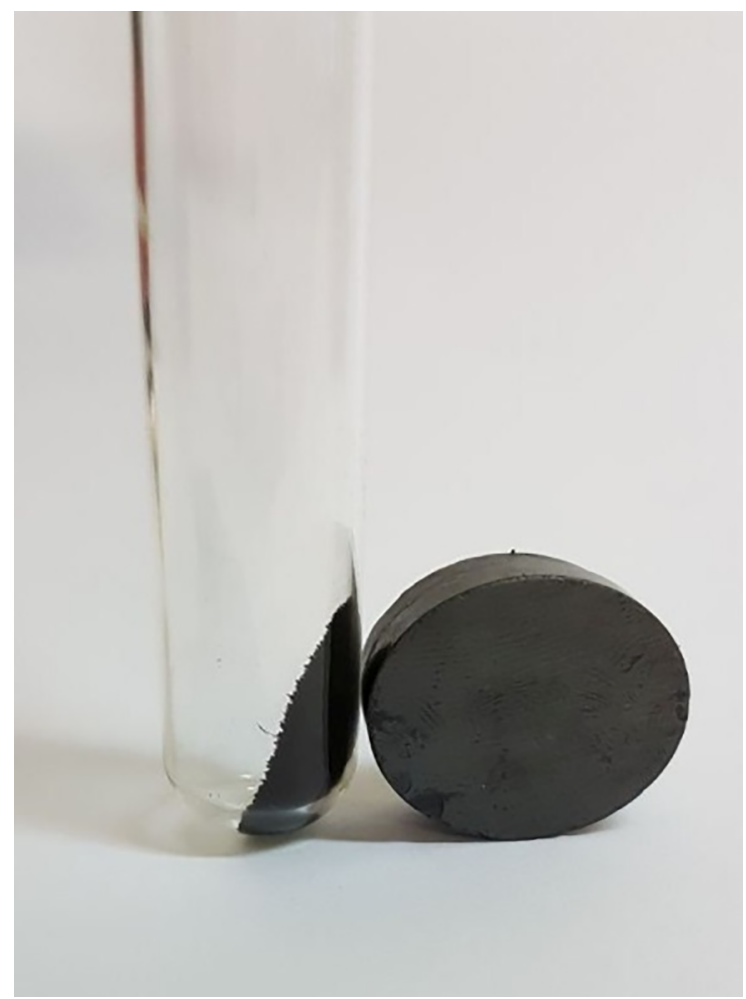

Figure 7. Photographic image of magnetic $\mathrm{CoFe}_{2} \mathrm{O}_{4}$ particles.
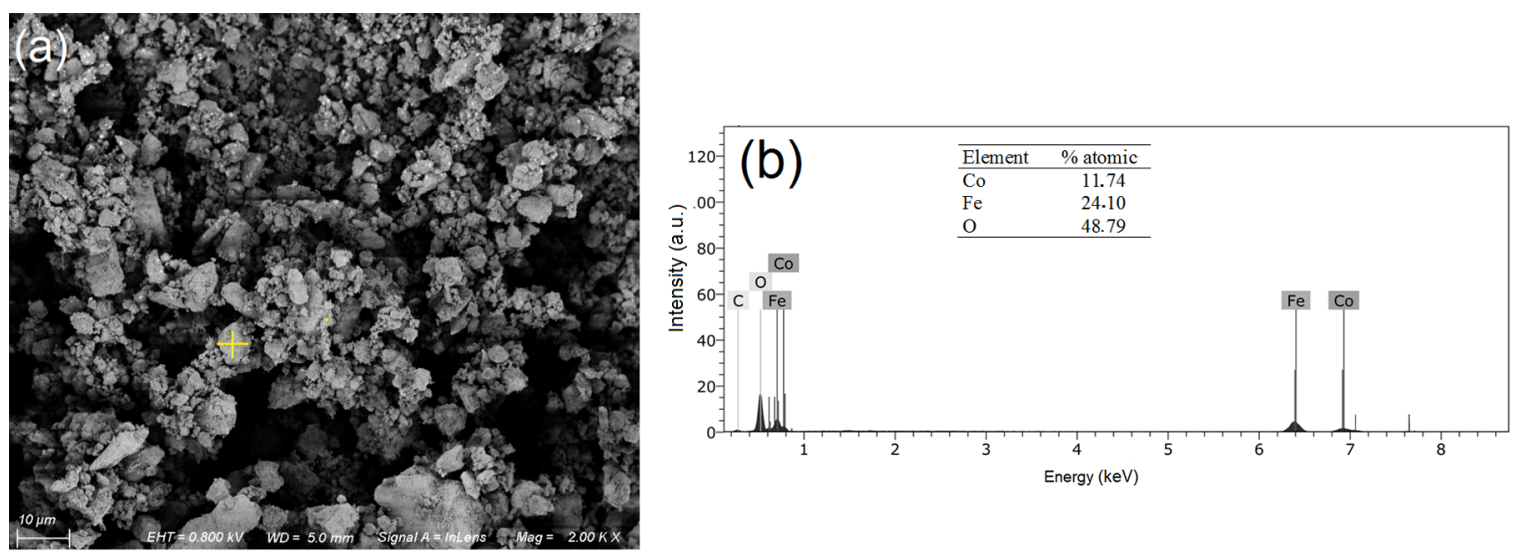

Figure 6. (a) SEM image and (b) EDS analysis of $\mathrm{CoFe}_{2} \mathrm{O}_{4}$ sample 
oxidation potential $(2.80 \mathrm{eV})$ compared to the molecular ozone $(2.07 \mathrm{eV})^{19}$.

Figure 12 shows the mineralization profiles of melanoidin as a function of reaction time by the non-catalytic $\left(\mathrm{O}_{3}\right)$ and catalytic $\left(\mathrm{O}_{3} / \mathrm{CoFe}_{2} \mathrm{O}_{4}\right)$ ozonation processes. It is known that a more extended reaction time is necessary to obtain a

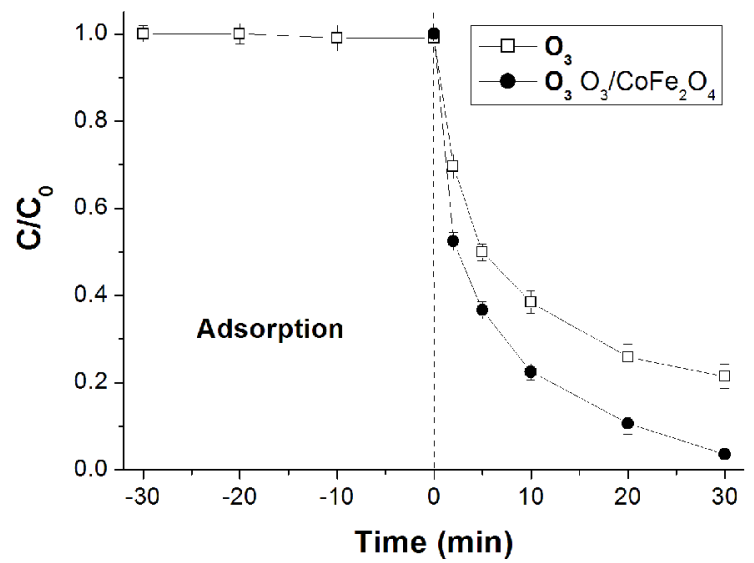

Figure 8. Comparison of melanoidin decolorization by the noncatalytic $\left(\mathrm{O}_{3}\right)$ and catalytic $\left(\mathrm{O}_{3} / \mathrm{CoFe}_{2} \mathrm{O}_{4}\right)$ ozonation processes.

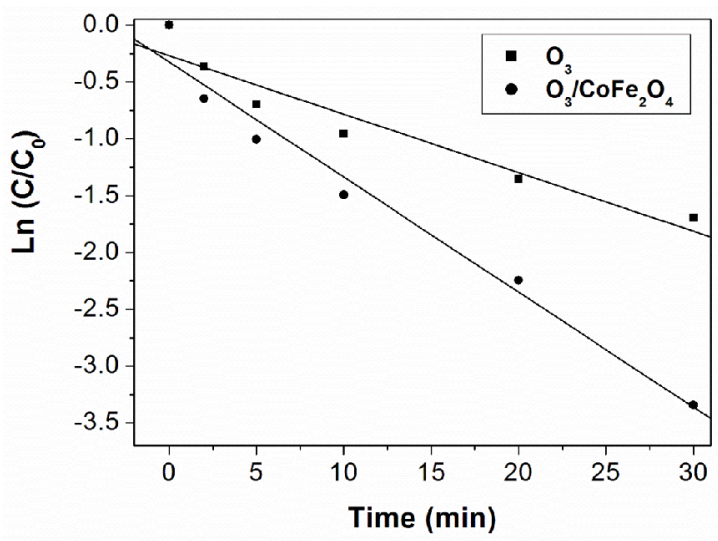

Figure 9. Pseudo-first-order plots for the melanoidin decolorization by non-catalytic $\left(\mathrm{O}_{3}\right)$ and catalytic $\left(\mathrm{O}_{3} / \mathrm{CoFe}_{2} \mathrm{O}_{4}\right)$ ozonation. high mineralization of an organic molecule from aqueous solution ${ }^{45,46}$. Therefore, the $\mathrm{O}_{3} / \mathrm{CoFe}_{2} \mathrm{O}_{4}$ system showed about $80 \%$ removal of TOC at $180 \mathrm{~min}$, whereas the non-catalytic $\left(\mathrm{O}_{3}\right)$ process showed about $60 \%$ removal of TOC. These mineralization results for both the processes corroborate those obtained for the melanoidin decolorization, where the presence of the $\mathrm{CoFe}_{2} \mathrm{O}_{4}$ catalyst is primordial for a superior activity in the melanoidin degradation.

Based on the experimental observations as aforementioned and those reported in literature using other materials as catalysts ${ }^{51,52}$, a simplified general mechanism for the melanoidin ozonation using $\mathrm{CoFe}_{2} \mathrm{O}_{4}$ as catalyst, included an possible indirect and a direct oxidation, could be depicted as follows. The reaction starts with the $\mathrm{O}_{3}$ adsorption on the surface catalyst followed by its decomposition, producing free radicals $\left(\cdot \mathrm{O}_{2} \mathrm{H}, \cdot \mathrm{O}_{2}^{-}\right)$, as shown in Equation $(2)^{53} \cdot \bullet_{2}^{-}$ radical is a highly selective catalyst for the decomposition of $\mathrm{O}_{3}$ in water, so it reacts with another molecule of $\mathrm{O}_{3}$ producing the radical $\bullet^{\mathrm{O}_{3}}$, according to Equation (3) ${ }^{53} \cdot \bullet^{-} \mathrm{O}_{3}^{-}$ decomposes upon protonation into $\bullet \mathrm{OH}$ radicals ${ }^{52}$, as show in Equations (4) and (5). Therefore, $\bullet O H$ radicals, which are highly reactive and non-selective species, quickly react

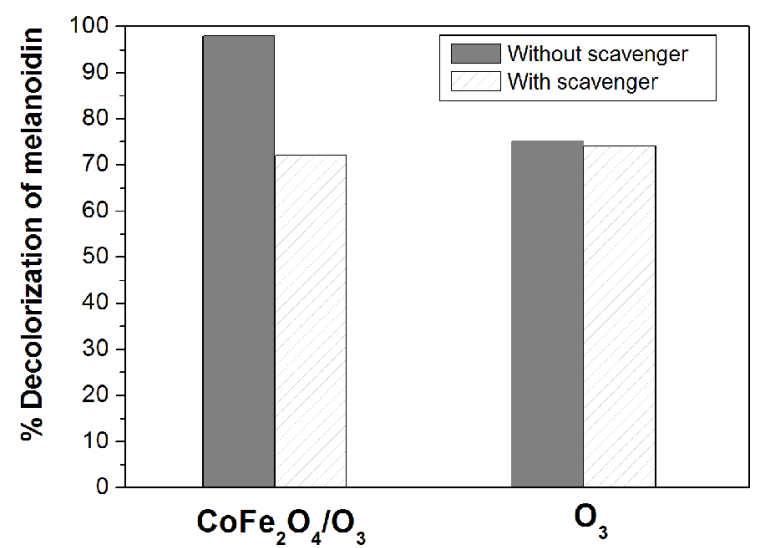

Figure 11. Decolorization efficiency of melanoidin by $\mathrm{CoFe}_{2} \mathrm{O}_{4} /$ $\mathrm{O}_{3}$ and $\mathrm{O}_{3}$ processes at 30 min of reaction time without and with scavenger (isopropanol).

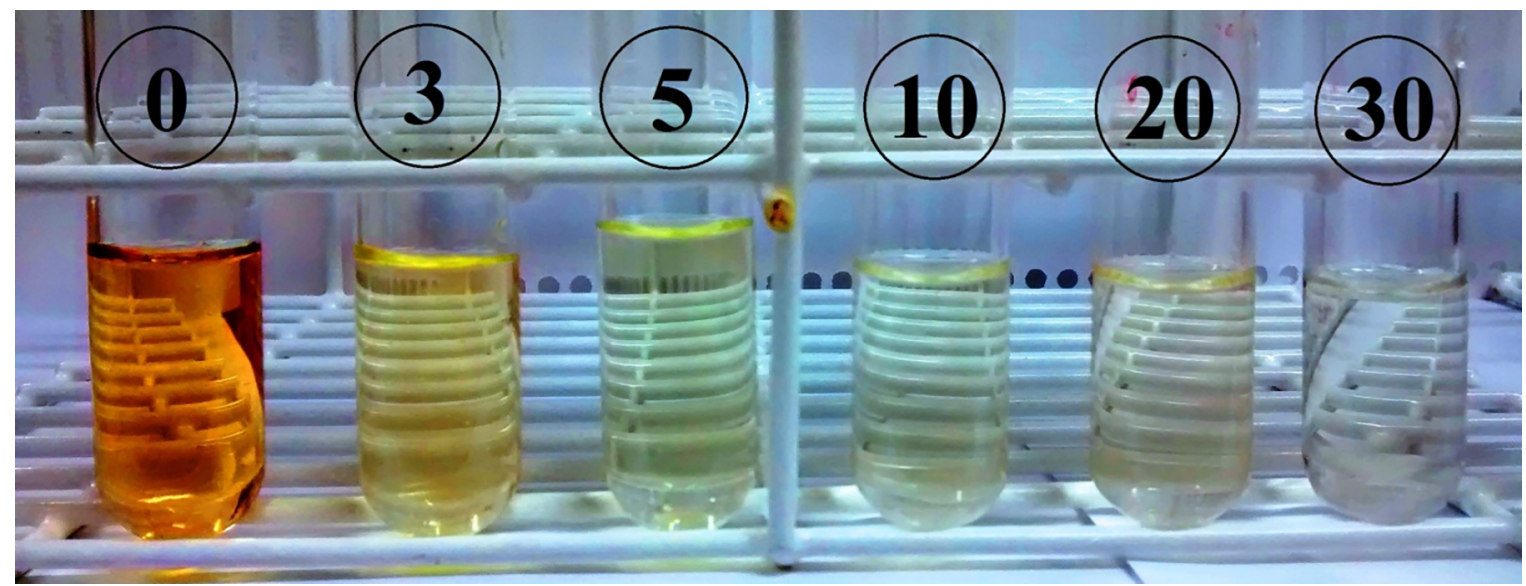

Figure 10. Photographic image of melanoidin solutions collected during the heterogeneous catalytic ozonation $\left(\mathrm{O}_{3} / \mathrm{CoFe}_{2} \mathrm{O}_{4}\right)$ until 30 min of reaction time. 


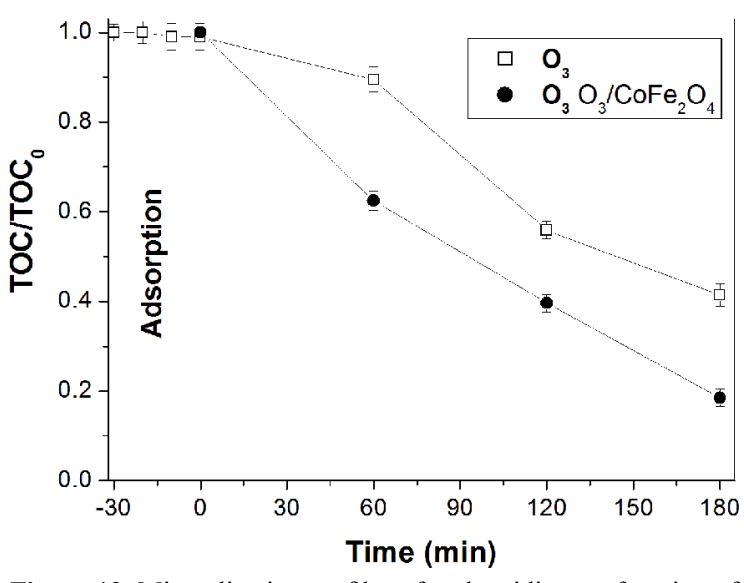

Figure 12. Mineralization profiles of melanoidin as a function of reaction time by the non-catalytic $\left(\mathrm{O}_{3}\right)$ and catalytic $\left(\mathrm{O}_{3} / \mathrm{CoFe}_{2} \mathrm{O}_{4}\right)$ ozonation processes.

with melanoidin leading to its degradation (Equation 6). Moreover, the $\mathrm{O}_{3}$ that has not been decomposed into $\bullet \mathrm{OH}$ radicals is probably dissolved in the aqueous medium and can oxidize directly the melanoidin.

$$
\begin{array}{r}
\mathrm{COFe}_{2} \mathrm{O}_{4^{-}} \mathrm{OH}+\mathrm{O}_{3} \rightarrow \cdot \mathrm{O}_{2} \mathrm{H}+\cdot \mathrm{O}_{2^{-}} \\
\mathrm{O}_{3}+\cdot \mathrm{O}_{2^{-}} \rightarrow \bullet \mathrm{O}_{3^{-}}+\mathrm{O}_{2} \\
\cdot \mathrm{O}_{3^{-}}+\mathrm{H}+\rightarrow \cdot \mathrm{O}_{3} \mathrm{H} \\
\cdot \mathrm{O}_{3} \mathrm{H} \rightarrow \mathrm{O}_{2}+\bullet \mathrm{OH}
\end{array}
$$

- $\mathrm{OH}+$ Melanoidin $\rightarrow$ deg radation products (6) $\left(\mathrm{CO}_{2}+\mathrm{H}_{2} \mathrm{O}+\right.$ int ermediates $)$

\section{Conclusions}

Solvothermal method employed in this work produced $\mathrm{CoFe}_{2} \mathrm{O}_{4}$ particles with a predominantly mesoporous structure containing a high surface area $\left(116 \mathrm{~m}^{2} \mathrm{~g}^{-1}\right)$. The ozonation process with $\mathrm{CoFe}_{2} \mathrm{O}_{4}$ showed a higher decolorization and mineralization of the melanoidin compared to $\mathrm{O}_{3}$ alone, being attributed to generation of $\bullet \mathrm{OH}$ radicals in reaction medium. A reaction mechanism was proposed in this work in order to elucidate the melanoidin degradation by catalytic ozonation. In summary, the $\mathrm{CoFe}_{2} \mathrm{O}_{4}$-catalyzed ozonation reaction proving to be a promising process for the application in the treatment of melanoidin present in several distillery wastewaters for its further safe disposal into aquatic ecosystems.

\section{Acknowledgement}

The authors wish to thank for the technical support of Postgraduate Program in Chemical Engineering at Federal University of Santa Maria (Brazil), and financial support of CNPq (Brazil).

\section{References}

1. Kalavathi DF, Uma L, Subramanian G. Degradation and metabolization of the pigment-melanoidin in distillery effluent by the marine cyanobacterium Oscillatoria boryana BDU 9218. Enzyme and Microbial Technology. 2001;29(4/5):246-251.

2. Coca M, García MT, González G, Peña M, García JA. Study of colored components formed in sugar beet processing. Food Chemistry. 2004;86(3):421-433.

3. Chandra R, Bharagava RN, Rai V. Melanoidins as major colourant in sugarcane molasses based distillery effluent and its degradation. Bioresources Technology. 2008;99(11):46484660 .

4. Peña M, Coca M, González G, Rioja R, García MT. Chemical oxidation of wastewater from molasses fermentation with ozone. Chemosphere. 2003;51(9):893-900.

5. Kumar P, Chandra R. Decolourisation and detoxification of synthetic molasses melanoidins by individual and mixed cultures of Bacillus spp. Bioresources Technology. 2006;97(16):20962102.

6. Foletto EL, Weber CT, Bertuol DA, Mazutti MA. Application of Papaya Seeds as a Macro-/Mesoporous Biosorbent for the Removal of Large Pollutant Molecule from Aqueous Solution: Equilibrium, Kinetic, and Mechanism Studies. Separation Science and Technology. 2013;48(18):2817-2824.

7. Dwyer J, Lant P. Biodegradability of DOC and DON for UV/ $\mathrm{H} 2 \mathrm{O} 2$ pre-treated melanoidin based wastewater. Biochemical Engineering Journal. 2008;42(1):47-54.

8. Oliveira JS, Mazutti MA, Urquieta-González EA, Foletto EL, Jahn SL. Preparation of Mesoporous Fe2O3-Supported ZSM-5 Zeolites by Carbon-Templating and their Evaluation as PhotoFenton Catalysts to Degrade Organic Pollutant. Materials Research. 2016;19(6):1399-1406.

9. Battiston S, Rigo C, Severo EC, Mazutti MA, Kuhn RC, Gündel A, et al. Synthesis of zinc aluminate (ZnAl2O4) spinel and its application as photocatalyst. Materials Research. 2014;17(3):734738 .

10. Pignatello JJ. Dark and photoassisted iron3+catalyzed degradation of chlorophenoxy herbicides by hydrogen peroxide. Environmental Science and Technology. 1992;26(5):944-951.

11. Sillanpää M, Chaker Ncibi M, Matilainen A. Advanced oxidation processes for the removal of natural organic matter from drinking water sources: A comprehensive review. Journal of Environmental Management. 2018;208:56-76. 
12. Miklos DB, Remy C, Jekel M, Linden KG, Drewes JE, Hübner U. Evaluation of advanced oxidation processes for water and wastewater treatment - A critical review. Water Research. 2018;139:118-131.

13. Cruz-Alcalde A, Sans C, Esplugas S. Priority pesticide dichlorvos removal from water by ozonation process: Reactivity, transformation products and associated toxicity. Separation and Purification Technology. 2018;192:123-129.

14. Chelme-Ayala P, El-Din MG, Smith DW. Kinetics and mechanism of the degradation of two pesticides in aqueous solutions by ozonation. Chemosphere. 2010;78(5):557-562.

15. Ghuge SP, Saroha AK. Catalytic ozonation for the treatment of synthetic and industrial effluents - Application of mesoporous materials: A review. Journal of Environmental Management. 2018;211:83-102.

16. Coca M, Peña M, González G. Variables affecting efficiency of molasses fermentation wastewater ozonation. Chemosphere. 2005;60(10):1408-1415.

17. Shahidi D, Roy R, Azzouz A. Advances in catalytic oxidation of organic pollutants - Prospects for thorough mineralization by natural clay catalysts. Applied Catalysis B: Environmental. 2015;174-175:277-292.

18. Khuntia S, Majumder SK, Ghosh P. Catalytic ozonation of dye in a microbubble system: Hydroxyl radical contribution and effect of salt. Journal of Environmental Chemical Engineering. 2016;4(2):2250-2258

19. Nawrocki J, Kasprzyk-Hordern B. The efficiency and mechanisms of catalytic ozonation. Applied Catalysis B: Environmental. 2010;99(1-2):27-42.

20. Bai Z, Yang Q, Wang J. Catalytic ozonation of sulfamethazine using $\mathrm{Ce} 0.1 \mathrm{Fe} 0.9 \mathrm{OOH}$ as catalyst: Mineralization and catalytic mechanisms. Chemical Engineering Journal. 2016;300:169176.

21. Nawaz F, Xie Y, Xiao J, Cao H, Ghazi ZA, Guo Z, et al. The influence of the substituent on the phenol oxidation rate and reactive species in cubic $\mathrm{MnO} 2$ catalytic ozonation. Catalysis Science \&Technology. 2016;6(21):7875-7884.

22. Wang Y, Yang W, Yin X, Liu Y. The role of Mn-doping for catalytic ozonation of phenol using Mn/?-A12O3nanocatalyst: Performance and mechanism. Journal of Environmental Chemical Engineering. 2016;4(3):3415-3425.

23. Xing S, Lu X, Liu J, Zhu L, Ma Z, Wu Y. Catalytic ozonation of sulfosalicylic acid over manganese oxide supported on mesoporous ceria. Chemosphere. 2016;144:7-12.

24. Zhang T, Croué JP. Catalytic ozonation not relying on hydroxyl radical oxidation: A selective and competitive reaction process related to metal-carboxylate complexes. Applied Catalysis B: Environmental. 2014;144: 831-839.

25. Ernst M, Lurot F, Schrotter JC. Catalytic ozonation of refractory organic model compounds in aqueous solution by aluminum oxide. Applied Catalysis B: Environmental. 2004;47(1):15-25.

26. Tong SP, Liu WP, Leng WH, Zhang QQ. Characteristics of $\mathrm{MnO}_{2}$ catalytic ozonation of sulfosalicylic acid and propionic acid in water. Chemosphere. 2003;50(10):1359-1364.
27. Mashayekh-Salehi A, Moussavi G, Yaghmaeian K. Preparation, characterization and catalytic activity of a novel mesoporous nanocrystalline $\mathrm{MgO}$ nanoparticle for ozonation of acetaminophen as an emerging water contaminant. Chemical Engineering Journal. 2017;310(Pt 1):157-169.

28. Chen C, Yan X, Yoza BA, Zhou T, Li Y, Zhan Y, et al. Efficiencies and mechanisms of ZSM5 zeolites loaded with cerium, iron, or manganese oxides for catalytic ozonation of nitrobenzene in water. Science of the Total Environment. 2018;612:1424-1432.

29. Zeng YF, Liu ZF, Qin ZZ. Decolorization of molasses fermentation wastewater by $\mathrm{SnO} 2$-catalyzed ozonation. Journal of Hazardous Materials. 2009;162(2-3):682-687.

30. Dai Q, Wang J, Chen J, Chen J. Ozonation catalyzed by cerium supported on activated carbon for the degradation of typical pharmaceutical wastewater. Separation and Purification Technology. 2014;127:112-120.

31. Pocostales P, Álvarez P, Beltrán FJ. Catalytic ozonation promoted by alumina-based catalysts for the removal of some pharmaceutical compounds from water. Chemical Engineering Journal. 2011;168(3):1289-1295.

32. Li X, Yao JH, Qi JY. Degradation of Organic Pollutants in water by Catalytic Ozonation. Chemical Research in Chinese Universities. 2007;23(3):273-275.

33. Afshar LE, Chaibakhsh N, Moradi-Shoeili Z. Treatment of wastewater containing cytotoxic drugs by $\mathrm{CoFe}_{2} \mathrm{O}_{4}$ nanoparticles in Fenton/ozone oxidation process. Separation Science and Technology. 2018. DOI: 10.1080/01496395.2018.1461113

34. Zhang FZ, Wei CH, Wu KY, Zhou HT, Hu Y, Preis S. Mechanistic evaluation of ferrite $\mathrm{AFe}_{2} \mathrm{O}_{4}(\mathrm{~A}=\mathrm{Co}, \mathrm{Ni}, \mathrm{Cu}$, and $\mathrm{Zn})$ catalytic performance in oxalic acid ozonation. Applied Catalysis A: General. 2017;547:60-68.

35. Dahiya J, Singh D, Nigam P. Decolourisation of synthetic and spentwash melanoidins using the white-rot fungus Phanerochaete chrysosporium JAG-40. Bioresources Technology. 2001;78(1):9598.

36. Kalam A, Al-Sehemi AG, Assiri M, Du G, Ahmad T, Ahmad I, et al. Modified solvothermal synthesis of cobalt ferrite ( $\mathrm{CoFe} 2 \mathrm{O} 4)$ magnetic nanoparticles photocatalysts for degradation of methylene blue with $\mathrm{H}_{2} \mathrm{O}_{2}$ /visible light. Results in Physics. 2018;8:1046-1053.

37. Srivastava V, Kohout T, Sillanpää M. Potential of cobalt ferrite nanoparticles ( $\mathrm{CoFe} 2 \mathrm{O} 4)$ for remediation of hexavalent chromium from synthetic and printing press wastewater. Journal of Environmental Chemical Engineering. 2016;4(3):2922-2932.

38. Zhao Y, Ma X, Xu P, Wang H, Liu Y, He A. Elemental mercury removal from flue gas by $\mathrm{CoFe} 2 \mathrm{O} 4$ catalyzed peroxymonosulfate. Journal of Hazardous Materials. 2018;341:228-237.

39. Reddy MP, Mohamed AMA, Zhou XB, Du S, Huang Q. A facile hydrothermal synthesis, characterization and magnetic properties of mesoporous $\mathrm{CoFe}_{2} \mathrm{O}_{4}$ nanospheres. Journal of Magnetism and Magnetic Materials. 2015;388:40-44.

40. de Oliveira RS, de Brito BS, Kulesza J, Alves S Jr, Barros BS. Tunable photoluminescence of nanostructured $\mathrm{LaPO}_{4}: \mathrm{Eu}^{3+} / \mathrm{Tb}^{3+}$ synthesized via a microwave-assisted ethylene glycol route. Ceramics International. 2017;43(11):8276-8283. 
41. Anchieta C, Cancelier A, Mazutti MA, Jahn SL, Kuhn RC, Gündel A, et al. Effects of Solvent Diols on the Synthesis of $\mathrm{ZnFe}_{2} \mathrm{O}_{4}$ Particles and Their Use as Heterogeneous PhotoFenton Catalysts. Materials (Basel). 2014;7(9):6281-6290.

42. Amiri M, Salavati-Niasari M, Pardakhty A, Ahmadi M, Akbari A. Caffeine: A novel green precursor for synthesis of magnetic $\mathrm{CoFe}_{2} \mathrm{O}_{4}$ nanoparticles and $\mathrm{pH}$-sensitive magnetic alginate beads for drug delivery. Materials Science \& Engineering: C. 2017;76:1085-1093.

43. Waldron RD. Infrared Spectra of Ferrites. Physical Reviews. 1955;99(6):1727-1735.

44. Zhang R, Sun L, Wang Z, Hao W, Cao E, Zhang Y. Dielectric and magnetic properties of $\mathrm{CoFe}_{2} \mathrm{O}_{4}$ prepared by sol-gel auto-combustion method. Materials Research Bulletin. 2018;98:133-138.

45. Anchieta CG, Sallet D, Foletto EL, da Silva SS, ChiavoneFilho O, do Nascimento CAO. Synthesis of ternary zinc spinel oxides and their application in the photodegradation of organic pollutant. Ceramics International. 2014;40(3):41734178 .

46. Anchieta CG, Severo EC, Rigo C, Mazutti MA, Kuhn RC, Muller EI, et al. Rapid and facile preparation of zinc ferrite $\left(\mathrm{ZnFe}_{2} \mathrm{O}_{4}\right)$ oxide by microwave-solvothermal technique and its catalytic activity in heterogeneous photo-Fenton reaction. Materials Chemistry and Physics. 2015;160:141-147.
47. Kim SB, Hayase F, Kato H. Decolorization and Degradation Products of Melanoidins on Ozonolysis. Agricultural and Biological Chemistry. 1985;49(3):785-792.

48. Floresyona D, Goubard F, Aubert PH, Lampre I, Mathurin J, Dazzi A, et al. Highly active poly(3-hexylthiophene) nanostructures for photocatalysis under solar light. Applied Catalysis B: Environmental. 2017;209:23-32.

49. Soltani T, Lee BK. Improving heterogeneous photo-Fenton catalytic degradation of toluene under visible light irradiation through Ba-doping in $\mathrm{BiFeO}_{3}$ nanoparticles. Journal of Molecular Catalysis A: Chemical. 2016;425:199-207.

50. Huang CK, Wu T, Huang CW, Lai CY, Wu MY, Lin YW. Enhanced photocatalytic performance of $\mathrm{BiVO}_{4}$ in aqueous $\mathrm{AgNO}_{3}$ solution under visible light irradiation. Applied Surface Science. 2017;399:10-19.

51. Ren Y, Dong Q, Feng J, Ma J, Wen Q, Zhang M. Magnetic porous ferrospinel $\mathrm{NiFe}_{2} \mathrm{O}_{4}$ : A novel ozonation catalyst with strong catalytic property for degradation of di-n-butyl phthalate and convenient separation from water. Journal of Colloid and Interface Science. 2012;382(1):90-96.

52. Liu X, Zhou Z, Jing G, Fang J. Catalytic ozonation of Acid Red B in aqueous solution over a Fe-Cu-O catalyst. Separation and Purification Technology. 2013;115:129-135.

53. Van Geluwe S, Braeken L, Van der Bruggen B. Ozone oxidation for the alleviation of membrane fouling by natural organic matter: A review. Water Research. 2011;45(12):3551-3570. 